\title{
Reacciones musculares faciales ante imágenes con diferente contenido social. Un índice fisiológico de empatía afectiva
}

\author{
Facial muscle reactions to pictures with different social content.
}

\author{
A physiological index of affective empathy \\ Carlos Gantiva ${ }^{1}$, Rocío Cendales $^{2}$, Maite Díaz ${ }^{3}$ y Yesenia González ${ }^{4}$ \\ ${ }^{1}$ Doctor en Psicología Clínica y de la Salud. Profesor asociado del Departamento de Psicología \\ de la Universidad de los Andes, Bogotá, Colombia. \\ E-mail: c.gantiva@uniandes.edu.co,cgantiva@gmail.com \\ ${ }^{2}$ Psicóloga. Universidad de San Buenaventura, sede Bogotá, Colombia. \\ ${ }^{3}$ Psicóloga. Universidad de San Buenaventura, sede Bogotá, Colombia. \\ ${ }^{4}$ Psicóloga. Universidad de San Buenaventura, sede Bogotá, Colombia. \\ La presente investigación fue financiada por la Universidad de San Buenaventura, \\ sede Bogotá (Ref. CHS-12-10). \\ Departamento de Psicología, Universidad de los Andes. Bogotá, Colombia.
}

\section{Resumen}

La empatía tiene dos componentes, el afectivo y el cognitivo. La empatía afectiva es la capacidad para sintonizarse afectivamente con las emociones que experimentan otras personas. Su medición se ha hecho, tradicionalmente, a través de medidas de auto-reporte, sin embargo, algunos estudios de población latinoamericana han utilizado medidas fisiológicas de la empatía afectiva. Adicionalmente, se ha planteado la hipótesis de que las personas expuestas a contenido gráfico violento (ej., conflicto armado) pueden estar desensibilizadas hacia este tipo de estímulos. Por ello, el objetivo del presente estudio fue evaluar la actividad de los músculos cigomático y corrugador ante imágenes con diferente contenido social, con el fin de establecer la validez de estas medidas fisiológicas como indicadores objetivos de empatía afectiva. Se registró la actividad electromiográfica de estos músculos faciales en 60 sujetos (30 con alta y 30 con baja empatía afectiva), mientras observaban imágenes con contenido social positivo, neutral y negativo. Los resultados mostraron que los participantes con alta empatía afectiva respondieron con mayor actividad del músculo cigomático ante imágenes sociales positivas y con mayor actividad del músculo corrugador ante imágenes sociales negativas, en comparación con los participantes con baja empatía afectiva. También se encontró una relación positiva y significativa entre los puntajes en la escala de preocupación empática y la actividad de los músculos cigomático y corrugador ante imágenes positivas y negativas, respectivamente. Los resultados sugieren que la actividad electromiográfica de los músculos faciales es un indicador objetivo de empatía afectiva y se recomienda utilizarlo para aumentar la validez de los estudios en este campo. No se encontró evidencia de desensibilización ante estímulos sociales 
aversivos en esta muestra.

Palabras clave: empatía; indicador; cigomático; corrugador; electromiografía

\section{Abstract}

Empathy has two components, the affective and the cognitive component. Affective empathy is the ability to emotionally tune into the emotions that other people experience. Its measurement has been done, traditionally, through self-report measures, however, there are some studies in Latin American population that have used physiological measures of affective empathy. Additionally, it has been hypothesized that people exposed to violent graphic content (e.g., armed conflict) may be desensitized to this type of stimulus. In this context, the objective of the present study was to evaluate the activity of the zygomatic and corrugator muscles to pictures with different social content, in order to establish the validity of these physiological measures as objective indicators of affective empathy. The electromyographic activity of these facial muscles was recorded in 60 subjects ( 30 with high affective empathy and 30 with low affective empathy), while observing pictures with positive, neutral and negative social content of the International Affective Picture System (IAPS). The results showed that the participants with high affective empathy responded with greater zygomatic muscle activity to positive social pictures $\left(F_{2.96}=5.93, p=.01\right.$, $\left.\eta_{\mathrm{p}}{ }^{2}=.11\right)$ and with greater corrugator muscle activity to negative social pictures $\left(F_{2,96}=\right.$ $\left.4.85, p=.02, \eta_{\mathrm{p}}{ }^{2}=.09\right)$, in comparison with participants with low affective empathy. The correlation and regression analyzes show a positive and significant relationship between the scores in the empathic concern scale of the Interpersonal Reactivity Index (IRI) and the activity of the zygomatic muscle to positive social pictures $\left(\beta=.39, R^{2}=.15, t=3.00\right.$, $p=.004)$, and the corrugator muscle activity to negative social pictures $\left(\beta=.27, R^{2}=.07\right.$, $t=1.99, p=.05)$. The results suggest that the electromyographic activity of the facial muscles is an objective indicator of affective empathy. The increase in the activity of the zygomatic and corrugator muscles in people with high affective empathy, when they observe stimuli with different social content, can be supported by the mirror neuron system and the theory of simulation as an explanatory mechanism of empathy. The mirror neuron system is composed of a complex network of visual areas in the occipital, parietal and temporal regions and two predominantly motor regions, which interact to generate movements similar to those observed, in this case the facial expressions of the stimuli. This response in facial mimicry induces affective states similar to those observed, which leads to a response of affective empathy. Finally, the results of the present study do not support the hypothesis of a desensitization in the participants to negative social stimuli due to the fact of being Colombian, because independently of the level of affective empathy, all of them responded with greater activity of the corrugator muscle to negative social pictures in comparison with neutral and positive pictures. However, as shown in the results, this response was significantly higher in participants with high affective empathy. This result cannot be generalized to the entire Colombian population, given the small size of the sample and its origin. Overall, the results suggest that responses of the zygomatic and corrugator muscles to stimuli with different social content are reliable indicators of affective empathy, and can be used as physiological markers of this kind of empathy in neuroscience and psychophysiology research. No evidence of desensitization was found toward aversive social stimuli in this sample.

Keywords: empathy; indicator; zygomatic; corrugator; electromyography.

\section{Introducción}

La empatía es la habilidad para entender y responder a los mensajes emocionales de las 
demás personas (Decety y Jackson, 2004). Está dividida en dos componentes, la empatía afectiva, que es el proceso por el cual la respuesta emocional de otros genera una reacción similar en el observador (sintonía afectiva o contagio emocional) y la empatía cognitiva, que es la habilidad para adoptar el punto de vista de la otra persona (teoría de la mente) (Lamm, Batson y Decety, 2007; Tabernero y Politis, 2016). De esta forma, la empatía comprende una ruta de ascenso (bottom-up) de resonancia afectiva y una ruta de descenso (top-down) de procesos cognitivos, las cuales son influenciadas por otras variables como la motivación (Decety, 2011).

En la neurociencia cognitiva, se considera que la empatía depende de estructuras cerebrales superiores, aunque sus sustratos fisiológicos subyacentes son necesariamente compartidos con aspectos más generales de la emoción y la sociabilidad, que se ubican en estructuras cerebrales inferiores y del sistema nervioso autónomo (Carter, Harris y Porges, 2009; Porges, 2007).

La habilidad de usar información afectiva para predecir el comportamiento de los demás o regular el propio comportamiento hace de la empatía un elemento fundamental para la adaptación social y el desarrollo moral (Vachon, Lynam y Johnson, 2014). Una de las principales suposiciones con respecto al papel de la empatía en las relaciones humanas es que inhibe los comportamientos antisociales (Jolliffe y Farrington, 2004; Miller y Eisenberg, 1988) y facilita la conducta prosocial (Eisenberg y Miller, 1987). Por ejemplo, los sujetos con conducta antisocial, violencia o agresión sexual son descritos como poco empáticos (Marshall, Hudson, Jones y Fernández, 1995; Miller y Eisenberg, 1988). La baja empatía también se relaciona con los síndromes externalizantes incluidos en el DSM V (American Psychiatric Association, 2013), tales como los trastornos de conducta, el trastorno de personalidad antisocial y el trastorno narcisista de la personalidad.

A pesar de la importancia de la empatía para el ajuste social de los individuos y la explicación de algunos comportamientos disfuncionales, la mayoría de los estudios en este campo se han desarrollado a través de medidas de auto-reporte. Por ejemplo, el meta-análisis desarrollado por Vachon et al. (2014), con 86 estudios realizados con población adulta desde 1960, identificó que solo el 7 \% utilizaron medidas objetivas de empatía (ej. pruebas de laboratorio). Ninguno utilizó medidas fisiológicas como índices de empatía afectiva o cognitiva.

Cuatro meta-análisis que han evaluado la posible relación entre empatía y agresividad (Jolliffe y Farrington, 2004; Lovetty Sheffield, 2007; Miller y Eisenberg, 1988; Vachon et al., 2014) han encontrado evidencia contradictoria. En todos se ha concluido que una posible causa de la inconsistencia de los datos es el uso limitado de medidas objetivas de empatía, como por ejemplo las pruebas de laboratorio o el registro de respuestas fisiológicas.

Diferentes investigaciones muestran evidencia a favor del uso de medidas fisiológicas para el estudio de la empatía. Por ejemplo, las personas con alta empatía afectiva responden con mayor actividad del músculo cigomático ante rostros alegres y con mayor actividad del músculo corrugador ante rostros de ira (Dimberg, Andréasson y Thunberg, 2011; Dimberg y Thunberg, 2012; Hühnel, Fölster, Werheid y Hess, 2014). Estas respuestas fisiológicas reflejan el sistema motivacional activado por los estímulos (mayor actividad del músculo cigomático indica un estado motivacional apetitivo y mayor actividad del músculo corrugador un estado motivacional aversivo) (Bradley, Codispoti, Cuthbert y Lang, 2001), por lo cual son índices fisiológicos de la sintonía afectiva entre el observador y la respuesta emocional expresada por las personas en las imágenes.

Este mecanismo ha sido previamente descrito en los estudios sobre contagio emocional (Hatfield, Cacioppo y Rapson, 1992; MacDonald, 2003), en donde el proceso inicia con la percepción del rostro del otro individuo, continúa con la respuesta de mímica 
facial que sirve como mecanismo de retroalimentación para la propia persona y la induce a un estado emocional similar, lo que finaliza en una respuesta de empatía afectiva y posteriormente, empatía cognitiva. Este proceso está soportado a nivel neurobiológico por el sistema de neuronas espejo que valida la teoría de la simulación como mecanismo para el desarrollo de la empatía (Gallese, 2001; Gallese y Goldman, 1998).

La empatía se da como resultado de la interacción entre sus dos componentes (i.e., afectivo y cognitivo); de hecho, se ha encontrado una correlación positiva entre empatía afectiva y cognitiva (Pérez-Albeniz y de Paul, 2003). Sin embargo, la empatía afectiva ocurre antes que la empatía cognitiva (Decety y Meyer, 2008). Esto se ha demostrado a través de estudios de enmascaramiento, en donde la rápida exposición $(30 \mathrm{~ms})$ a expresiones faciales de ira y alegría producen, respectivamente, respuestas automáticas (i.e., sin procesamiento cognitivo), en los músculos corrugador y cigomático (Dimberg, Thunberg y Elmehed, 2000). De esta forma, la actividad de estos músculos han demostrado ser indicadores confiables de procesos automáticos de mímica facial (primer paso para la empatía afectiva, Hessy Blairy, 2001).

En países latinoamericanos son escasas las investigaciones que han estudiado la empatía bajo esta metodología. La mayor parte suelen utilizar instrumentos de auto-reporte (Pineda et al., 2013; Plata, Riveros y Moreno, 2010) o técnicas cualitativas (Cortés, Torres, LópezLópez, Pérez y Pineda-Marín, 2016), las cuales tienen limitaciones debidas al efecto de la deseabilidad social (Vachon et al., 2014). Esto ha generado que el estudio de la empatía a través del registro de respuestas fisiológicas tenga poca difusión.

Adicionalmente, en Colombia (país en donde se obtuvo la muestra del presente estudio), existe la hipótesis de que debido al conflicto armado que se ha presentado durante los últimos 50 años y a la sobreexposición a imágenes al respecto en la población general, se ha generado una desensibilización a estímulos con alto contenido social-afectivo negativo, así como un déficit en la respuesta de empatía (Barreto, Borja, Serrano y López-López, 2009; López y Sabucedo, 2007). Sin embargo, no existe evidencia de este fenómeno a través del registro de respuestas fisiológicas.

Por todo lo expuesto anteriormente, el objetivo del presente estudio fue comparar la actividad de los músculos cigomático y corrugador ante imágenes con diferente contenido social afectivo en personas con baja y alta empatía afectiva. Esto se hizo con el fin de confirmar $\mathrm{su}$ validez como correlatos fisiológicos de empatía afectiva y evaluar la hipótesis de una posible desensibilización hacia estímulos con alto contenido social aversivo en poblaciones que han estado expuestas a contenido gráfico violento. En caso de que esta última hipótesis fuera cierta, se esperaría que los participantes, independientemente de su nivel de empatía afectiva, presenten una actividad del músculo corrugador de intensidad baja y no significativamente distinta ante imágenes con diferente contenido social (i.e., positivo, neutro, negativo).

Debido a los resultados encontrados en otras poblaciones (Dimberg et al., 2011; Dimberg y Thunberg, 2012; Hühnel et al., 2014) y a la evidencia sobre el carácter automático de las respuestas del músculo corrugador y cigomático ante estímulos con diferente contenido social afectivo (Dimberg et al., 2000), la hipótesis del presente estudio fue que las personas con alta empatía afectiva tendrían mayor actividad de los músculos cigomático y corrugador ante imágenes con contenido social positivo y negativo, respectivamente, en comparación con las personas con baja empatía afectiva.

\section{Método}

\section{Participantes}

Los participantes se seleccionaron a través de un muestreo no probabilístico intencional. La muestra estuvo conformada por 60 parti- 
cipantes pertenecientes a población general con un rango de edad entre 18 y 30 años, los cuales fueron divididos en dos grupos: baja empatía afectiva $(n=30)$ y alta empatía afectiva $(n=30)$, de acuerdo con el puntaje obtenido en la escala de Preocupación Empática, principal índice de empatía afectiva del Índice de Reactividad Interpersonal (IRI) (Davis, 1980; Vachon et al., 2014). Debido a que los puntajes en empatía afectiva suelen ser mayores en mujeres que en hombres, la selección de los participantes se hizo a través de una división de medianas (mediansplit) separadas por sexo; de lo contrario, la muestra de sujetos con alta empatía afectiva hubiera quedado conformada en gran parte por mujeres (Dimberg et al., 2011).

En la Tabla 1 se resumen las características sociodemográficas básicas y los puntajes en la escala Preocupación Empática de los participantes. Como criterios de exclusión al estudio se tuvo en cuenta el reporte de enfermedades físicas o psicológicas, estar bajo tratamiento farmacológico y tener problemas de visión no corregidos. Todos los participantes firmaron el formato de consentimiento informado y el estudio fue aprobado por el Comité de Ética de la institución.

Tabla 1

Características sociodemográficas y puntaje en Preocupación Empática por grupo.

\begin{tabular}{cccccc}
\hline Variables & $\begin{array}{c}\text { Alta empatía } \\
\text { afectiva }\end{array}$ & $\begin{array}{c}\text { Baja empatía } \\
\text { afectiva }\end{array}$ & $\chi^{2}$ & $t$ & $P$ \\
\hline Edad en años, $M(D E)$ & $21.48(2.99)$ & $20.78(3.33)$ & & -.78 & .43 \\
Sexo: \% hombres /\% mujeres & $63 / 37$ & $60.9 / 39.1$ & .02 & & .87 \\
Preocupación empática, $M(D E)$ & $21(3.01)$ & $14.74(2.37)$ & & -8.05 & $<.001$ \\
\hline
\end{tabular}

$D E$ : Desviación estándar.

\section{Estímulos y manipulación experimental}

Se seleccionaron 36 imágenes del Sistema Internacional de Imágenes Afectivas ${ }^{1}$ ([IAPS] Lang, Bradley y Cuthbert, 2008). De estas, 12 representaban interacciones sociales positivas (ej. personas felices o sonriendo), 12 representaban interacciones sociales neutrales (ej. personas sin expresiones emocionales) y 12 representaban interacciones sociales negativas (ej. personas llorando, con dolor o sufriendo).

Para la selección de las imágenes del IAPS se utilizaron los valores normativos de la población colombiana (Gantiva, Guerra, y Vila, 2011), a partir de los puntajes en las dimensiones de valencia y arousal (los cuales van de 1 a 9). Se utilizaron los siguientes criterios: a) las imágenes con contenido social positivo no debían tener diferencias significativas en arousal en comparación con las imágenes con contenido social negativo $(M=5.22, D E=.64 ; M=5.76, D E=.55$; $\left.F_{(2,35)}=20.61, p=.08\right)$; b) las imágenes con contenido social positivo fueron seleccionadas de aquellas con altos puntajes en valencia, mientras que las imágenes con contenido social negativo tenían bajos puntajes en valencia $(M=7.20, D E=$ $.45 ; M=2.31, D E=.47 ; F_{(2,35)}=272.58$, $p<.001)$; y c) las imágenes con contenido social

\footnotetext{
${ }^{1}$ Imágenes con contenido social positivo: 2071, 2347, 4628, 2395, 2151, 2511, 2274, 4622, 2155, 4626, 2158, 2224. Imágenes con contenido social neutral: 2032, 2191, 2302, 2308, 2377, 2382, 2393, 2441, 2489, 2745.1, 6837, 7493. Imágenes con contenido social negativo: 2095, 2375.1, 2683, 3005.1, 3101, 6315, 6520, 6555, 6563, 9163, 9413, 9635.1
} 
neutral tenían puntajes intermedios en valencia y arousal $(M=5.65, D E=.62 ; M=4.27$, $D E=.52)$, con diferencias significativas en valencia y arousal con las otras dos categorías de imágenes (todas las $p<.002$ ).

Las imágenes fueron presentadas por seis segundos en un monitor de pantalla plana de 19 pulgadas localizado aproximadamente a 60 centímetros del participante. Se organizaron cuatro órdenes diferentes para la presentación de las imágenes; cada orden estuvo conformado por 36 ensayos contrabalanceados, con la restricción de no presentar dos imágenes consecutivamente de la misma categoría de contenido social. Cada uno de los órdenes fue presentado a 15 participantes. El intervalo entre ensayos varió aleatoriamente entre $10 \mathrm{y}$ 14 segundos. La presentación de las imágenes fue programada con el software E-Prime 2.0 (Psychology Software Tools, PA, USA). El experimento se llevó a cabo en una sola sesión con una duración aproximada de 45 minutos.

\section{Registro de medidas fisiológicas}

La actividad de los músculos cigomático y corrugador se registró con un equipo PowerLab 26T (AD Instruments, Australia). La electromiografía (EMG) fue registrada con electrodos de $4 \mathrm{~mm}$ de $\mathrm{Ag} / \mathrm{AgCl}$ colocados sobre los músculos cigomático y corrugador izquierdos (Fridlund y Cacioppo, 1986). Se utilizó un filtro de banda entre 10 a $1000 \mathrm{~Hz}$ y la señal se integró y rectificó con una constante de tiempo de $500 \mathrm{~ms}$. Ambas respuestas se adquirieron con una tasa de muestreo de $1000 \mathrm{~Hz}$ y se registraron en microvoltios $(\mu \mathrm{v})$.

\section{Medidas de auto-reporte}

Para la evaluación de la empatía afectiva se utilizó la escala de preocupación empática de la versión validada en Colombia del IRI (Davis, 1980; Pineda et al., 2013). El IRI es un instrumento compuesto por 28 ítems con opción de respuesta de 0 a 4 que se califica a partir de la suma de cada ítem en cada una de las cuatro escalas (toma de perspectiva, fantasía, preocupación empática y estrés personal por empatía). La escala de preocupación empática es la principal escala de empatía afectiva (Vachon et al., 2014). La consistencia interna de esta escala fue de .77 .

\section{Procesamiento de datos y análisis estadístico}

La actividad de los músculos cigomático y corrugador se obtuvo a partir del cálculo del área bajo la curva de la respuesta de cada músculo durante la presentación de cada imagen; para esto, al valor de cada muestra durante el período de observación de la imagen (6 s), se le restó la actividad media durante el segundo previo al inicio de la imagen. Posteriormente, se obtuvo el promedio de todos los puntajes diferenciales por cada categoría de imagen.

El análisis de los datos fisiológicos se hizo a través de dos ANOVAs $2 \times 3$ bifactoriales mixtas, con la variable Grupo (Baja empatía / Alta empatía) como factor intersujeto, la variable Imagen (contenido social positivo, neutral y negativo) como factor intrasujeto y cada respuesta fisiológica como variable dependiente. Los análisis post-hoc se hicieron a través de la comparación de pares utilizando la corrección Bonferroni. Se reporta el tamaño del efecto para cada ANOVA $\left(\boldsymbol{\eta}_{\mathrm{p}}{ }^{2}\right.$; pequeño $\geq$ .01 , medio $\geq .06$, grande $\geq .14$; Cohen, 1988) y para las comparaciones de pares ( $d$ Cohen).

Finalmente, con el objetivo de establecer la relación entre los puntajes en la escala Preocupación Empática (empatía afectiva) y las respuestas de los músculos cigomático y corrugador ante las imágenes con contenido social afectivo (i.e., positivas y negativas), se realizó un análisis de correlación de Pearson y un análisis de regresión lineal. El nivel de significancia para todos los análisis fue de .05 y se llevaron a cabo en el programa estadístico SPSS 20.0. 


\section{Resultados}

\section{Actividad del músculo cigomático}

El ANOVA identificó un efecto principal significativo para Imagen $\left(F_{2,96}=13.16, p=\right.$ $\left..001, \eta_{\mathrm{p}}{ }^{2}=.21\right)$. Las imágenes con contenido social positivo generaron mayor actividad del músculo cigomático $(M=4.28, D E=7.65)$, en comparación con las imágenes con contenido social neutral $(M=.81, D E=1.92, p=.001, d$ Cohen $=.62)$ y negativo $(M=.27, D E=.99, p$ $=.003, d$ Cohen $=.73)$. También se encontró un efecto principal significativo para Grupo $\left(F_{1,48}=5.13, p=.02, \eta_{\mathrm{p}}^{2}=.09\right)$; en general las personas con alta empatía afectiva respondieron con mayor actividad del músculo cigomático $(M=2.66, D E=4.25)$, en comparación con los participantes con baja empatía afectiva $(M=.77, D E=1.91, p=.02, d$ Cohen $=.57)$. Sin embargo, como se identificó en la interacción significativa Grupo $\times$ Imagen $\left(F_{2,96}=5.93, p=.01, \eta_{\mathrm{p}}{ }^{2}=.11\right)$, únicamente las imágenes sociales positivas generaron una actividad significativamente mayor del músculo cigomático en los participantes con alta empatía afectiva en comparación con los participantes con baja empatía afectiva $(p=.01, d$ Cohen $=.71)($ ver Figura $1 \mathrm{~A} \mathrm{y}$ Tabla 2).

\section{Actividad del músculo corrugador}

El ANOVA identificó un efecto principal significativo para Imagen $\left(F_{2,96}=19.79, p<\right.$ $\left..001, \eta_{\mathrm{p}}{ }^{2}=.29\right)$. Las imágenes con contenido social negativo generaron mayor actividad del músculo corrugador $(M=3.40, D E=5.39)$, en comparación con las imágenes con contenido social neutral $(M=.91, D E=2.02, p<.001, d$ Cohen $=.61)$ y positivo $(M=-.43, D E=1.26$, $p<.001, d$ Cohen $=.97)$ y las imágenes con contenido social neutral mayor actividad que las imágenes positivas $(p=.003, d$ Cohen $=$ .79). El factor Grupo no fue significativo $\left(F_{1,48}\right.$ $\left.=2.86, p=.09, \eta_{\mathrm{p}}^{2}=.05\right)$.

Como se observa en la Figura 1B, el efecto de interacción Grupo $\times$ Imagen fue significativo $\left(F_{2,96}=4.85, p=.02, \eta_{\mathrm{p}}{ }^{2}=.09\right)$, solamente las imágenes con contenido social negativo generaron una actividad significativamente mayor del músculo corrugador en los participantes con alta empatía afectiva en comparación con los participantes con baja empatía afectiva $(p=.04, d$ Cohen $=.61)($ Tabla 2$)$.

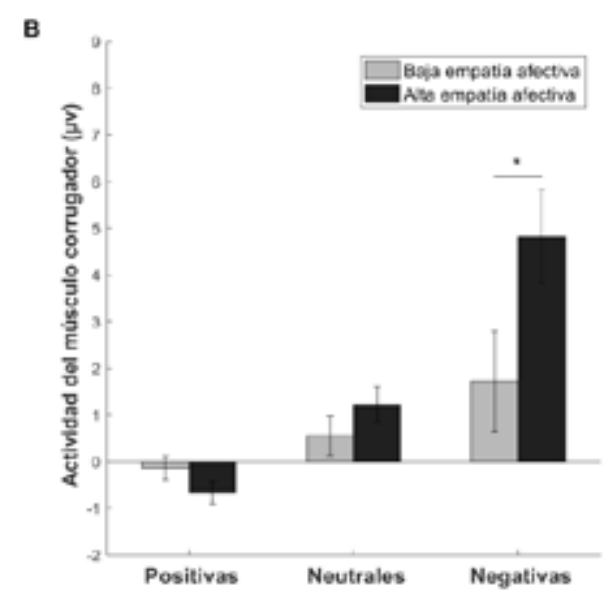

Figura 1.

Actividad de los músculos cigomático (panel A) y corrugador (panel B) ante imágenes con contenido social positivo, neutral y negativo en personas con baja y alta empatía afectiva. 
Tabla 2

Magnitud de la actividad de los músculos cigomático y corrugador ante imágenes con diferente contenido social (positivo, neutral y negativo) en personas con alta y baja empatía afectiva.

\begin{tabular}{cccc}
\hline & & $\begin{array}{c}\text { Alta empatía } \\
\text { afectiva } \\
M(\mathrm{DE})\end{array}$ & $\begin{array}{c}\text { Baja empatía } \\
\text { afectiva } \\
M(\mathrm{DE})\end{array}$ \\
\hline \multirow{2}{*}{$\begin{array}{c}\text { Músculo } \\
\text { cigomático }\end{array}$} & Positivas & $6.61(9.22)$ & $1.55(3.91)$ \\
\cline { 2 - 4 } & Neutrales & $1.06(2.47)$ & $.52(.90)$ \\
\cline { 2 - 4 } Músculo & Negativas & $.29(1.06)$ & $.26(.93)$ \\
\cline { 2 - 4 } corrugador & Positivas & $-.67(1.66)$ & $-.14(.34)$ \\
\cline { 2 - 4 } & Neutrales & $1.22(2.57)$ & $.55(1.03)$ \\
\cline { 2 - 4 } & Negativas & $4.82(6.74)$ & $1.72(2.38)$ \\
\hline
\end{tabular}

Nota: La magnitud de la respuesta esta expresada en $\boldsymbol{\mu v}$.

\section{Relación entre los puntajes en empatía afectiva y la EMG facial}

El análisis de correlación mostró que los puntajes en la escala Preocupación Empática tienen una relación positiva y significativa con la actividad del músculo cigomático ante imágenes sociales positivas $(r=.39, p=.004)$ y con la actividad del músculo corrugador ante imágenes sociales negativas $(r=.27$, $p=.05)$. El coeficiente de regresión estan- darizado $(\beta)$ revela una pendiente positiva y significativa entre el puntaje en la escala Preocupación Empática (empatía afectiva) y la actividad del músculo cigomático ante imágenes con contenido social positivo $\left(\beta=.39, R^{2}=.15, t=3.00, p=.004\right.$ ) (Figura $2 \mathrm{~A})$ y una pendiente positiva y significativa con la actividad del músculo corrugador ante imágenes con contenido social negativo $\left(\beta=.27, R^{2}=.07, t=1.99, p=.05\right)$ (Figura 2B).
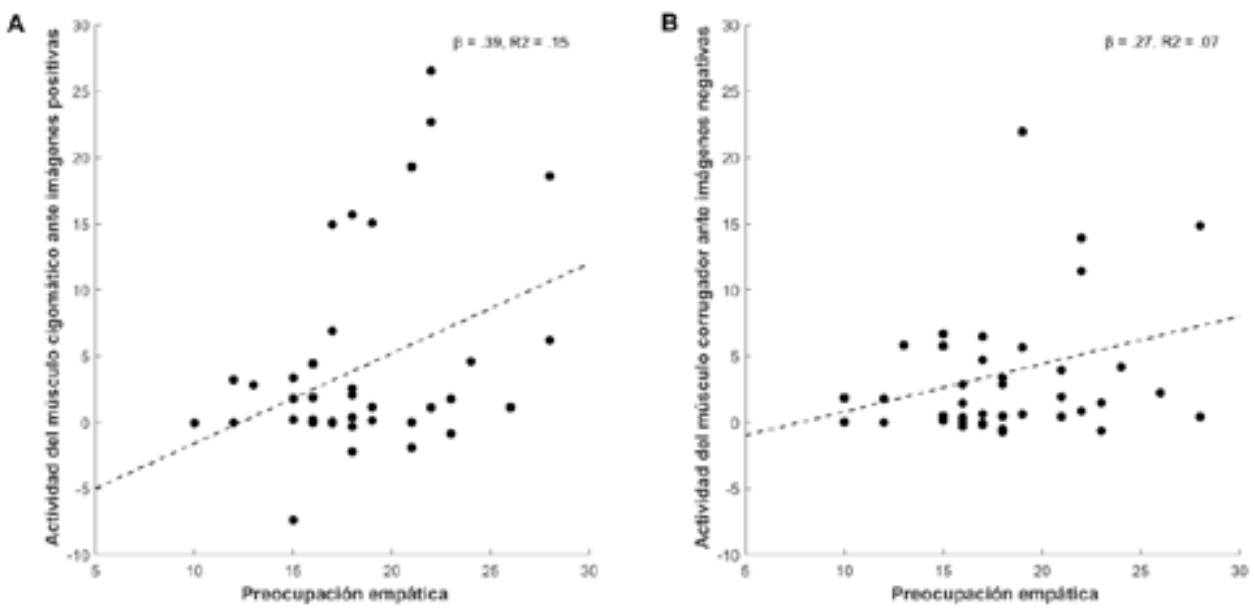

Figura 2. Diagramas de dispersión de puntos para la relación entre puntajes en Preocupación Empática y la actividad del músculo cigomático ante imágenes sociales positivas (A) y la actividad del músculo corrugador ante imágenes sociales negativas (B). 


\section{Discusión}

La presente investigación tuvo por objetivo comparar la actividad de los músculos cigomático y corrugador ante imágenes con diferente contenido social en personas con baja y alta empatía afectiva, con el fin de validar esta metodología y su uso como índice fisiológico de este tipo de empatía. Los resultados mostraron que los participantes con alta empatía afectiva respondieron con mayor actividad del músculo cigomático ante imágenes positivas y mayor actividad del músculo corrugador ante imágenes negativas. Asimismo, los puntajes en la escala preocupación empática, que mide empatía afectiva, están relacionados positiva y significativamente con la actividad de los músculos cigomático y corrugador ante imágenes positivas y negativas, respectivamente. Sin embargo, esta relación fue mayor con la actividad del músculo cigomático ante imágenes sociales positivas en comparación con la actividad del músculo corrugador ante imágenes negativas.

La mayor actividad de los músculos cigomático y corrugador en los participantes con alta empatía afectiva sugiere que experimentan un mayor afecto positivo ante imágenes sociales agradables y un mayor afecto negativo ante imágenes sociales desagradables (Bradley et al., 2001; Gantiva y Camacho, 2016; Gantiva, Guerra y Vila, 2015; Michelini, Acuña y Godoy, 2015), lo que refleja una sintonía afectiva entre el observador y el contenido social del estímulo, requisito fundamental para la empatía afectiva (Decety y Jackson, 2004; Lamm, Batson y Decety, 2007).

Estudios previos han reportado resultados similares; por ejemplo, Dimberg et al. (2011) encontraron en personas con alta empatía afectiva mayor actividad de los músculos cigomático y corrugador ante expresiones faciales de alegría e ira, respectivamente, lo que indica mayor mímica facial en las personas con alta empatía afectiva. Estas diferencias se observan desde los $500 \mathrm{~ms}$ (Dimberg y Thunberg, 2012) e incluso sin que la persona sea consciente de lo que observó (Dimberg et al., 2000).

El incremento en la actividad de los músculos cigomático y corrugador en personas con alta empatía afectiva, cuando observan estímulos con diferente contenido social, puede estar soportado por el sistema de neuronas espejo (Gallese, 2001) y la teoría de la simulación como mecanismo explicativo de la empatía (Gallese y Goldman, 1998). El sistema de neuronas espejo está compuesto por una red compleja de áreas visuales en las regiones occipital, parietal y temporal y dos regiones predominantemente motoras (parte anterior del lóbulo parietal inferior y el sector del lóbulo frontal conformado por el cortex premotor ventral más la región posterior del giro frontal inferior) (Acharya y Shukla, 2012; Rizzolatti y Craighero, 2004), las cuales interactúan para generar movimientos similares a los observados, en este caso las expresiones faciales de los estímulos. Esta respuesta de mímica facial induce estados afectivos similares a los observados lo cual desemboca en una respuesta de empatía afectiva.

En conjunto, los resultados de los diferentes estudios sugieren que las respuestas de los músculos cigomático y corrugador ante estímulos con diferente contenido social son indicadores confiables de empatía afectiva y pueden ser utilizados como marcadores fisiológicos en investigaciones en el campo de las neurociencias y la psicofisiología.

Finalmente, los resultados del presente estudio no apoyan la hipótesis de una desensibilización en los participantes ante estímulos sociales negativos (Barreto et al., 2009; López y Sabucedo, 2007), pues independientemente del nivel de empatía afectiva, todos respondieron con mayor actividad del músculo corrugador ante imágenes sociales negativas en comparación con las imágenes neutrales y positivas. Este resultado no puede ser generalizado a toda la población colombiana, dado el tamaño reducido de la muestra y su procedencia.

Los resultados de esta investigación deben ser analizados tomando en cuenta las 
siguientes limitaciones. Primero, solamente se utilizaron respuestas fisiológicas como índices de empatía afectiva; en futuros estudios se sugiere utilizar medidas fisiológicas de empatía cognitiva, como por ejemplo resonancia magnética funcional (Neumann y Westbury, 2011). Segundo, si bien se utilizaron medidas de auto-reporte y fisiológicas de empatía, existen otras metodologías para evaluarla; por ejemplo, respuestas conductuales ante inducción de estados afectivos en el laboratorio y lectura de gestos faciales (Vachon et al., 2014). El uso de diferentes metodologías y su correlación permitirán comprender de forma más integral el papel que tiene la empatía sobre el comportamiento.

Finalmente, la distribución de los sexos al interior de cada grupo no fue equitativa (mayor número de hombres que de mujeres), lo que conlleva a que los resultados sean más generalizables a los hombres. Sin embargo, se resalta que no hubo diferencias significativas en la distribución de sexos entre los grupos, lo cual favorece la validez interna de los resultados.

\section{Referencias bibliográficas}

Acharya, S. y Shukla, S. (2012). Mirror neurons: Enigma of the metaphysical modular brain. Journal of Natural Science, Biology, and Medicine, 3(2), 118-124. http://dx.doi. org/10.4103/0976-9668.101878

American Psychiatric Association. (2013). Diagnostic and statistical manual of mental disorders (5th ed.). Arlington, VA: American Psychiatric Publishing. $\quad$ http://dx.doi.org/10.1176/appi. books.9780890425596.744053

Barreto,I., Borja, H., Serrano, Y. y López-López, W. (2009). La legitimación como proceso en la violencia política, medios de comunicación y construcción de paz. Universitas Psychologica, 8(3), 733-748.

Bradley, M.M., Codispoti, M., Cuthbert, B., y Lang, P.J. (2001). Emotion and motivation I: Defensive and appetitive reactions in picture processing. Emotion, 1(3), 276-298. http:// dx.doi.org/10.1037/1528-3542.1.3.276

Carter, C.S., Harris, J. y Porges, S.W. (2009). Neural and evolutionary perspectives on empathy. En J. Decety y W. Ickes (Eds.), The social neuroscience of empathy (pp. 169-182). Cambridge, MA: MIT Press.

Cohen, J. (1988). Statistical power analysis for the behavioral sciences (2nd ed.). Hillsdale, NJ: Erlbaum.

Cortés, A., Torres, A., López-López, W., Pérez, D. y Pineda-Marín, C. (2016). Comprensiones sobre el perdón y la reconciliación en el contexto del conflicto armado colombiano. Psychosocial Intervention, 25(1), 19-25.

Davis, M.H. (1980). A multidimensional approach to individual differences in empathy. Recuperado de http://www.uv.es/ friasnav/ Davis 1980.pdf

Decety, J. (2011). Dissecting the neural mechanisms mediating empathy. Emotion Review, 3(1),92-108. doi:10.1177/1754073910374662.

Decety, J. y Jackson, P.L. (2004).The functional architecture of human empathy. Behavioral and Cognitive Neuroscience Reviews, 3(2), 71-100. http://dx.doi.org/10.1177/1534582304267187.

Decety, J. y Meyer, M. (2008). From emotion resonance to empathic understanding: A social developmental neuroscience account. Development and Psychopathology, 20(4), 1053-1080. http://dx.doi.org/10.1017/S0954579408000503

Dimberg, U., Andréasson, P. y Thunberg, M. (2011).Emotional empathy and facial reactions to facial expressions. Journal of Psychophysiology, 5(1), 26-31. http://dx.doi. org/10.1027/0269-8803/a000029

Dimberg, U. y Thunberg, M. (2012). Empathy, emotional contagion, and rapid facial reactions to angry and happy facial expressions. PsyCh Journal, 1(2), 118-127. http://dx.doi. org/10.1002/pchj.4

Dimberg, U., Thunberg, M. y Elmehed, K. (2000). Unconscious facial reactions to emotional facial expressions. Psychological Science, 11(1), 86-89.

Eisenberg, N. y Miller, P.A. (1987).The relation of empathy to prosocial and related behaviors. Psychological Bulletin, 101, 91-119. http:// 
dx.doi.org/10.1037/0033-2909.101.1.91

Fridlund, A.J. y Cacioppo, J.T. (1986). Guidelines for human electromyographic research. Psychophysiology, 23, 567-589.

Gallese, V. (2001).The 'shared manifold' hypothesis. From mirror neurons to empathy. Journal of Consciousness Studies, 8(5-6), 33-50.

Gallese, V. y Goldman, A. (1998). Mirror neurons and the simulation theory of mind-reading. Trends in CognitiveSciences, 2(12), 493-501.

Gantiva, C., Guerra, P. y Vila, J. (2011). Validación colombiana del sistema internacional de imágenes afectivas: evidencias del origen transcultural de la emoción. Acta Colombiana de Psicología, 14(2), 103-111.

Gantiva, C. y Camacho, K. (2016). Características de la respuesta emocional generada por las palabras: un estudio experimental desde la emoción y la motivación. Psychologia, 10(2), 55-62. http://dx.doi.org/10.21500/19002386.2550

Gantiva, C., Guerra, P. y Vila, J. (2015). Modulación del reflejo de sobresalto en población colombiana: evidencia de la interacción entre emoción y motivación. Universitas Psychologica, 14(1), 157-164. http://dx.doi. org/10.11144/Javeriana.upsy14-1.mrsp

Hatfield, E., Cacioppo, J.T. y Rapson, R. (1992). Primitive emotional contagion. En M.S. Clark (Ed.), Review of Personality and Social Psychology (pp.151-177). Newbury Park, CA: Sage.

Hess, U. y Blairy, S. (2001). Facial mimicry and emotional contagion to dynamic emotional facial expressions and their influence on decoding accuracy. International Journal of Psychophysiology, 40(2), 129-141.

Hühnel, I., Fölster, M., Werheid, K. y Hess, U. (2014). Empathic reactions of younger and older adults: No age related decline in affective responding. Journal of Experimental Social Psychology, 50, 136-143. http://dx.doi. org/10.1016/j.jesp.2013.09.011

Jolliffe, D. y Farrington, D.P. (2004). Empathy and offending: A systematic review and meta-analysis. Aggression and Violent Behavior, 9, 441-476. http://dx.doi.org/10.1016/j. avb.2003.03.001
Lamm, C., Batson, C.D. y Decety, J. (2007). The neural substrate of human empathy: Effects of perspective-taking and cognitive appraisal. Journal of Cognitive Neuroscience, 19(1), 42-58. $\quad$ http://dx.doi.org/10.1162/ jocn.2007.19.1.42.

Lang, P., Bradley, M.M. y Cuthbert, B.N. (2008). International affective picture system (IAPS): Affective ratings of pictures and instruction manual (Technical Report A-8). Gainesville, FL: University of Florida.

López, W. y Sabucedo, J.M. (2007). Culture of peace and mass media. European Psychologist, 12(2), 147-155. http://dx.doi. org/10.1027/1016-9040.12.2.147

Lovett, B.J. y Sheffield, R.A. (2007). Affective empathy deficits in aggressive children and adolescents: A critical review. Clinical Psychology Review, 27, 1-13. http://dx.doi. org/10.1016/j.cpr.2006.03.003

Marshall, W.L., Hudson, S.M., Jones, R. y Fernández, Y.M. (1995). Empathy in sex offenders. Clinical Psychology Review, 15, 99-113. $\quad$ http://dx.doi.org/10.1016/02727358\%2895\%2900002-7

MacDonald, A. (2003). I feel your pain (and joy): New theories about empathy. Brain Work, 13(4), 1-3.

Michelini, Y., Acuña, I. y Godoy, J.C. (2015). Características de la experiencia emocional inducida mediante fragmentos de películas en una muestra de jóvenes argentinos. Interdisciplinaria, 32(2), 367-382. http://dx.doi. org/10.16888/interd.2015.32.2.10

Miller, P.A. y Eisenberg, N. (1988).The relation of empathy to aggressive and externalizing/ antisocial behavior. Psychological Bulletin, 103, 324-344. http://dx.doi.org/10.1037/00332909.103.3.324

Neumann, D. y Westbury, R. (2011). The psychophysiological measurement of empathy. En D.J. Scapaletti (Ed.), Psychology of empathy (pp. 119-142). New York, NY: Nova Science.

Perez-Albeniz, A. y de Paul, J. (2003). Dispositional empathy in high-and low-risk parents for child physical abuse. Child Abuse and Neglect, 27(7), 769-780. http://dx.doi.org/10.1016/ 


\section{S0145-2134(03)00111-X}

Pineda, D.A., Aguirre-Acevedo, D.C., Trujillo, N., Valencia, A.M., Pareja, Á.,Tobón, C.,...e Ibáñez, A. (2013). Dimensiones de la empatía en excombatientes del conflicto armado colombiano utilizando una escala estandarizada. Revista Colombiana de Psiquiatría, 42(1), 9-28.

Plata, C., Riveros, M. y Moreno, J. (2010). Autoestima y empatía en adolescentes observadores, agresores y víctimas del bullying en un colegio del municipio de Chía. Psychologia, 4(2), 99-112.

Porges, S.W. (2007). The polyvagal perspective. Biological Psychology, 74, 116-143. http:// dx.doi.org/10.1016/j.biopsycho.2006.06.009
Rizzolatti, G. y Craighero, L. (2004). The mirrorneuron system. Annual Review of Neuroscience, 27, 169-192. http://dx.doi.org/10.1146/ annurev.neuro.27.070203.144230

Tabernero, M.E. y Politis, D.G. (2016). Reconocimiento facial de emociones básicas y su relación con la teoría de la mente en la variante conductual de la demencia frontotemporal. Interdisciplinaria, 33(1), 21-39. http://dx.doi. org/10.16888/interd.2016.33.1.2

Vachon, D.D., Lynam, D.R. y Johnson, J.A. (2014). The (non)relation between empathy and aggression: surprising results from a meta-analysis. Psychological Bulletin, 140(3), 751-773. http://dx.doi.org/10.1037/a0035236

Recibido: 29 de enero de 2018 Aceptado: 27 de noviembre de 2019 